Published in final edited form as:

Org Lett. 2018 September 07; 20(17): 5406-5409. doi:10.1021/acs.orglett.8b02318.

\title{
Transformation of $\mathbf{N}, \mathbf{N}$-Dimethylaniline $\mathbf{N}$-Oxides into Diverse Tetrahydroquinoline Scaffolds via Formal Povarov Reactions
}

\author{
Timothy S. Bush, Glenn P. A. Yap, William J. Chain * \\ Department of Chemistry \& Biochemistry, University of Delaware, Newark, Delaware 19716, \\ United States
}

\begin{abstract}
A one-pot protocol for the assembly of diversely functionalized tetrahydro-, hexahydrofuro-, hexahydropyrano-, and tetrahydrobenzofuroquinolines from $N, N$-dimethylaniline $N$-oxides and various electron-rich olefins in a tandem Polonovski-Povarov sequence is reported. Following activation of the $\mathrm{N}-\mathrm{O}$ bond with $\mathrm{Boc}_{2} \mathrm{O}$, an exocyclic iminium ion is unveiled upon exposure to tin(IV) chloride. A formal inverse-electron-demand aza-Diels-Alder cyclization generates the tetrahydroquinoline core of 29 examples in up to $92 \%$ yield.
\end{abstract}

\section{Graphical Abstract}
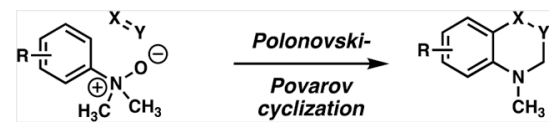

\begin{abstract}
The tetrahydroquinoline scaffold lies at the heart of countless natural products, biologically active materials, medicinal compounds, ligands, catalyst frameworks, and a myriad of other natural and synthetic materials. ${ }^{1}$ Convenient access to this special structure is impactful in a variety of fields and disciplines, and a number of approaches to the tetrahydroquinoline structure have been described. ${ }^{2}$
\end{abstract}

Modern strategies toward the synthesis of highly substituted tetrahydroquinolines include the hydrogenation of quinolines, ${ }^{3}$ tandem hydroamination-hydrogenation of alkynyl anilines, ${ }^{4}$ and the classical Povarov reaction ${ }^{5}$ which combines an aniline, an aldehyde, and some alkene component in a formal inverse-electron-demand aza-Diels-Alder ${ }^{6}$ reaction (Scheme 1, eqs 1-3). Each of these approaches is limited by the nature of the reactions and

\footnotetext{
*Corresponding Author: wchain@udel.edu.

Author Contributions

All experimental procedures were executed by T.B. X-ray crystallographic data was collected by G.Y.

The authors declare no competing financial interest.

Supporting Information

The Supporting Information is available free of charge on the ACS Publications website at DOI: 10.1021/acs.orglett.8b02318. Detailed experimental procedures, spectral data, and X-ray crystallographic data (PDF)

Accession Codes

CCDC 1847432-1847434 and 1847436-1847441 contain the supplementary crystallographic data for this paper. These data can be obtained free of charge via www.ccdc.cam.ac.uk/data_request/cif, or by emailing data_request@ccdc.cam.ac.uk, or by contacting The Cambridge Crystallographic Data Centre, 12 Union Road, Cambridge CB2 1EZ, UK; fax: +44 1223336033.
} 
the reagents required. For example, hydrogenation of quinolines can be achieved under the action of various transition metals ${ }^{7}$ or organocatalysts; ${ }^{8}$ however, the reaction conditions are often quite harsh, and the preparation of quinoline starting materials can be laborious (Scheme 1, eq 1). The tandem hydroamination-hydrogenation of alkynyl anilines is achieved under gold catalysis ${ }^{4}$ (and often relayed with an organocatalytic hydrogenation), which necessarily limits the scope of the available products to 2-substituted materials (Scheme 1, eq 2, substituent $\mathrm{R}_{2}$ ). The Povarov reaction relies upon the protic or Lewis acid mediated condensation of an aniline and an aldehyde followed by capture of the resultant aza-diene with an alkene (Scheme 1, eq 3); thus, the Povarov reaction is often limited to electron-rich anilines and alkene components. There are successful asymmetric variants of each of these strategies that further impinge upon the scope of the available substrates (e.g., by requiring structural features such as Lewis basic groups that facilitate catalyst binding). $3,4,7-9$

We report here a practical synthesis of the tetrahydroquinoline scaffold as part of our broader research program investigating the special reactivity of $\mathrm{N}, \mathrm{N}$-dialkylaniline $\mathrm{N}$-oxides (Scheme 1, eq 4). ${ }^{10}$ The aniline $N$-oxides undergo $O$-acylation events with a host of electrophiles, and we have developed chemistry by which the weak $\mathrm{N}-\mathrm{O}$ bond is excised in a Polonovski-type reaction to give an iminium ion. ${ }^{11}$ Following that event, the imine is captured by an electron-rich alkene, and the resultant cation is then attacked by the pendant aniline. Thus, the reaction constitutes the stepwise formal [4 +2] cycloaddition (aza-DielsAlder reaction) of the Povarov reaction. In the case of aniline $\mathrm{N}$-oxides, $\mathrm{O}$-acylation requires an electrophile that will not undergo the $\mathrm{N} \rightarrow \mathrm{C}$ group transfer we have previously described; ${ }^{10,11}$ elimination can be achieved efficiently under the action of a Lewis acid to give a stable iminium ion (Scheme 2). The elimination pathway is favored over group transfer by employing di-tert-butyl dicarbonate $\left(\mathrm{Boc}_{2} \mathrm{O}\right)$ as the acylating agent (which does not undergo $\mathrm{N} \rightarrow \mathrm{C}$ group transfer at a significant rate, Scheme $2 \mathrm{~b}, \mathbf{2} \rightarrow \mathbf{3 b}$ ), followed by treatment with tin(IV) chloride as a Lewis acid. The Lewis acid assisted elimination reaction to generate iminium ions proceeds cleanly on a variety of substituted $N, N$-dimethylaniline $N$-oxides (Scheme 2a, $\mathbf{2} \rightarrow \mathbf{3 a}$ ). We have successfully captured this electrophile with a variety of electron-rich vinyl ethers, thus restoring the electron-rich anilines $(\mathbf{3 a} \rightarrow \mathbf{4})$. The resultant cations are sufficiently stable to undergo intramolecular attack by the aniline $(\mathbf{4} \rightarrow$ 5) to give a variety of polycyclic scaffolds.

After the intramolecular attack by the aromatic ring, loss of a proton restores aromaticity (5 $\rightarrow \mathbf{6})$. We extensively screened Lewis acidic reaction conditions $\left(\mathrm{BF}_{3} \cdot \mathrm{OEt}_{2}, \mathrm{BCl}_{3}, \mathrm{FeCl}_{3}\right.$, $\mathrm{ZnBr}_{2}, \mathrm{CuBr}, \mathrm{CuI}, \mathrm{InCl}_{3}, \mathrm{TiCl}_{4}, \mathrm{SnCl}_{4}$, and $\mathrm{LiClO}_{4}$ ) and temperature profiles to support the cationic cyclization sequence and determined that tin(IV) chloride ( 0.25 equiv) in cold dichloromethane routinely afforded clean cyclized materials. As part of our study, we found these $N$-oxides to be far easier to handle and manipulate as complexes with $m$-chlorobenzoic acid. Following oxidation of the anilines with $m$-CPBA, ${ }^{10}$ the $N$-oxides cocrystallize with the acid byproduct to give robust crystalline solids that are bench stable and nonhygroscopic (see the Supporting Information, SI). Moreover, the $m$-chlorobenzoic acid does not interfere with the capture of iminium ions by exogenous nucleophiles, provided that excess activating agent is employed. For example, upon treatment of 4 -acetoxy- $N, N$-dimethylaniline $\mathrm{N}$-oxide 
(1a) with di-tert-butyl dicarbonate $\left(\mathrm{Boc}_{2} \mathrm{O}\right)$ and $4-(N, N$-dimethyl-amino)pyridine (DMAP) at $0{ }^{\circ} \mathrm{C}$, followed by cooling to $-94{ }^{\circ} \mathrm{C}$ and addition of tin(IV) chloride and ethyl vinyl ether, the cationic cascade reaction afforded the substituted tetrahydroquinoline $7 \mathbf{a}$ in $78 \%$ yield (Scheme 3). ${ }^{12}$ The reaction is tolerant of both electron-rich and electron-poor substituents on the aromatic ring, giving 4-ethoxy- $N$-methyl-tetrahydroquinolines in $42-78 \%$ yields in $5-6$ $\mathrm{h}$ at low temperature.

We then employed cyclic vinyl ethers in the Polonovski-Povarov reaction sequence and found these to be similarly reactive. By subjecting 2,3-dihydrofuran and 3,4-dihydro- $2 \mathrm{H}$ pyran to the same reaction conditions (Scheme 4), we obtained the polycyclic scaffolds 8 and 9 in $42-74 \%$ yields. The ring junctions of the furanoquinoline and pyranoquinoline products are formed exclusively as the cis-fused products as determined by ${ }^{1} \mathrm{H}$ NMR analysis, and we later confirmed these structural assignments by X-ray crystallography (8a, $\mathbf{8 e}, \mathbf{9 a}$, and $\mathbf{9 b}$, see SI).

Moreover, benzofurans are also sufficiently nucleophilic to participate in the cationic cyclization sequence, giving rise to tetracyclic products 10 in $41-87 \%$ yields (Scheme 5) and offering the opportunity to generate materials with two distinctly substituted aromatic residues (e.g., $10 \mathrm{~g}$ and $10 \mathrm{~h}$ ). The regiochemistry of attack utilizing benzofuran nucleophiles is inverted relative to their dihydrofuran equivalents, as was expected. ${ }^{13}$ The products form exclusively as the cis-fused ring junction, and these assignments were also confirmed crystallo-graphically (10a-c and 10e, see the SI).

In an effort to further expand the structural motifs accessible via the cationic cyclization sequence, we are exploring other less electron-rich nucleophiles, and we have identified allylic silanes ${ }^{14}$ as viable reaction participants (Scheme 6). ${ }^{15}$ The allylic silanes can engage the $N$-aryliminium ions, giving stabilized secondary carbocation intermediates, which undergo rapid ring closure. The allylic silanes offer the opportunity to generate diversely functionalized products 11, which were formed in 31-92\% yields under reaction conditions identical to those previously identified. Interestingly, the stereochemical outcome of these reactions with respect to the ring fusion appears to correlate with the olefin geometry of the starting materials, though our work with allylic silanes is ongoing. For example, when we employed $E$-aryl allylic silanes in the reaction sequence, we obtained the tetrahydroquinoline products 11c and 11d in $92 \%$ and $90 \%$ yields, respectively, as the transsubstituted products. We view these reactions as stepwise ring closure events, and we are further investigating the lifetime of the secondary cation intermediates under these reaction conditions.

We are working to further explore similar reactions with other allylic silanes and will report these and other new cycloaddition reactions in due course. Importantly, if the secondary cation intermediate is too stable, the reaction does not proceed beyond the initial capture of the iminium ion. For example, a silyl ketene acetal can capture the iminium ion in a Mannich-type ${ }^{16}$ reaction (Scheme 7a) directly analogous to our previous work in the synthesis of indolines (Scheme 7b). ${ }^{11}$ 
We have described a practical and convenient synthetic protocol for the rapid assembly of various tetrahydroquinoline scaffolds via Lewis acid assisted tandem Polonovski-Povarov cyclizations. The products are obtained in up to $92 \%$ yield in 5-6 h at low temperature, and these reactions represent a novel use of the special reactivity of $N, N$-dimethylaniline $N$ oxides. Owing to the abundance of commercially available anilines and electron-rich alkenes, this methodology will allow for the facile construction of numerous natural products, pharmaceutically relevant molecules, and other useful polycyclic scaffolds.

\title{
Supplementary Material
}

Refer to Web version on PubMed Central for supplementary material.

\section{ACKNOWLEDGMENTS}

\begin{abstract}
We gratefully acknowledge Mr. Chad E. Hatch (University of Delaware) for insightful conversations regarding this work and for manuscript preparation assistance. The University of Delaware (UD), the American Chemical Society Petroleum Research Fund (ACS PRF 54452-ND1), and the National Science Foundation (NSF CHE-1664954) are gratefully acknowledged for financial support. Spectral data were acquired at UD on instruments obtained with the assistance of NSF and NIH funding (NSF CHE0421224, CHE0840401, CHE1229234, CHE1048367; NIH S10 OD016267-01, S10 RR026962-01, P20GM104316, P30GM110758).
\end{abstract}

\section{REFERENCES}

(1). (a)Sridharan V; Suryavanshi PA; Menendez JC Chem. Rev 2011, 111, 7157. [PubMed: 21830756] (b)Barton DH; Nakanishi K; Cohn OM Comprehensive Natural Products Chemistry; Elsevier: Oxford, 1999; Vols. 1-9.

(2). (a)Keay JG In Comprehensive Organic Synthesis; Fleming I, Trost BM, Eds.; Pergamon: Oxford, 1991; p 579.(b)Katritzky AR; Rachwal S; Rachwal B Tetrahedron 1996, 52, 15031.

(3). (a)Glorius F Org. Biomol. Chem 2005, 3, 4171. [PubMed: 16294244] (b)Zhou Y-G Acc. Chem. Res 2007, 40, 1357. [PubMed: 17896823] (c)Wang D-S; Chen Q-A; Lu S-M; Zhou Y-G Chem. Rev 2012, 112, 2557. [PubMed: 22098109]

(4). (a)Du Y-L; Hu Y; Zhu Y-F; Tu Z-F; Han Z-Y; Gong L-ZJ Org. Chem 2015, 80, 4754.(b)Han Z-Y; Xiao H; Chen X-H; Gong L-ZJ Am. Chem. Soc 2009, 131, 9182.

(5). (a)Povarov LS Russ. Chem. Rev 1967, 36, 656For selected recent examples of Povarov reactions involving three-component couplings, see:.(b)Grieco PA; Bahsas A Tetrahedron Lett. 1988, 29, 5855.(c)Kobayashi S; Nagayama SJ Am. Chem. Soc 1996, 118, 8977.(d)Ma Y; Qian C; Xie M; Sun JJ Org. Chem 1999, 64, 6462.(e)Lavilla R; Bernabeu MC; Carranco I; Díaz JL Org. Lett 2003, 5, 717. [PubMed: 12605498] (f)Powell DA; Batey RA Tetrahedron Lett. 2003, 44, 7569. (g)Batey RA; Powell DA Chem. Commun 2001, 2362.(h)Yadav JS; Subba Reddy BV; Srinivas R; Madhuri C; Ramalingam T Synlett 2001, 2001, 240.(i)Legros J; Crousse B; Ourévitch M; Bonnet-Delpon D Synlett 2006, 2006, 1899 For selected recent examples of conceptually similar quinoline synthesis, see:(j)Reddy BVS; Grewal H Tetrahedron Lett. 2011, 52, 761.(k)Huo C; Chen F; Quan Z; Dong J; Wang Y Tetrahedron Lett. 2016, 57, 5127.(1)Bohórquez ARR; RomeroDaza J; Acelas M Synth. Commun 2016, 46, 338.

(6). Fringuelli F; Taticchi A In The Diels-Alder Reaction: Selected Practical Methods; John Wiley \& Sons: Sussex, 2002.

(7). (a)Wang W-B; Lu S-M; Yang P-Y; Han X-W; Zhou Y-GJ Am. Chem. Soc 2003, 125, 10536. (b)Zhao YJ; Wang YQ; Zhou YG Chin. J. Catal 2005, 26, 737.(c)Li Z-W; Wang T-L; He Y-M; Wang Z-J; Fan Q-H; Pan J; Xu L-J Org. Lett 2008, 10, 5265. [PubMed: 18954070] (d)Yang Z; Chen F; He Y-M; Yang N; Fan Q-H Catal. Sci. Technol 2014, 4, 2887.(e)Wang T; Zhuo L-G; Li Z; Chen F; Ding Z; He Y; Fan Q-H; Xiang J; Yu Z-X; Chan AS C. J. Am. Chem. Soc 2011, 133, 9878.(f)Li HY; Horn J; Campbell A; House D; Nelson A; Marsden SP Chem. Commun 2014, 50, 10222.(g)Wang C; Li C; Wu X; Pettman A; Xiao J Angew. Chem., Int. Ed 2009, 48, 6524.(h)Cai X-F; Huang W-X; Chen Z-P; Zhou Y-G Chem. Commun 2014, 50, 9588. 
(8). (a)Rueping M; Antonchick AR; Theissmann T Angew. Chem., Int. Ed 2006, 45, 3683.(b)Rueping M; Dufour J; Schoepke FR Green Chem. 2011, 13, 1084.(c)Guo Q-S; Du D-M; Xu J Angew. Chem., Int. Ed 2008, 47, 759.(d)Ren L; Lei T; Ye JX; Gong LZ Angew. Chem., Int. Ed 2012, 51, 771.(e)Han Z-Y; Xiao H; Chen X-H; Gong L-ZJ Am. Chem. Soc 2009, 131, 9182.

(9). For representative selected examples of asymmetric Povarov reactions, see:(a)Ishitani H; Kobayashi S Tetrahedron Lett. 1996, 37, 7357.(b)Sundararajan G; Prabagaran N; Varghese B Org. Lett 2001, 3, 1973. [PubMed: 11418027] (c)Akiyama T; Morita H; Fuchibe KJ Am. Chem. Soc 2006, 128, 13070.(d)Doyle AG; Jacobsen EN Chem. Rev 2007, 107, 5713. [PubMed: 18072808] (e)Liu H; Dagousset G; Masson G; Retailleau P; Zhu JJ Am. Chem. Soc 2009, 131, 4598.(f)Akiyama T; Morita H; Fuchibe KJ Am. Chem. Soc 2006, 128, 13070.(g)Zhao M-N; Yu L; Hui R-R; Ren Z-H; Wang Y; Guan Z ACS Catal. 2016, 6, 3473.

(10). (a)Lewis RS; Garza CJ; Dang AT; Pedro T-KA; Chain WJ Org. Lett 2015, 17, 2278. [PubMed: 25906358] (b)Reed H; Paul TR; Chain WJ J. Org. Chem 2018, DOI: 10.1021/acs.joc.8b01590.

(11). Nakashige ML; Lewis RS; Chain WJ Tetrahedron Lett. 2015, 56, 3531.

(12). Reactions are initially cooled to $-94{ }^{\circ} \mathrm{C}$ in order to suppress unproductive elimination reactions following the nucleophilic capture event that results in Mannich-type products.

(13). Abu-Hashem AA; Hussein HAR; Aly AS; Gouda MA Synth. Commun 2014, 44, 2899.

(14). McAtee JR; Yap GP; Watson DA J. Am. Chem. Soc 2014, 136, 10166. [PubMed: 25003502]

(15). For an alternative approach to similar products, see: Katritzky AR; Cui X; Long CJ Heterocycl. Chem 1999, 36, 371.

(16). (a)Heaney H In Comprehensive Organic Synthesis; Trost BM, Fleming I, Eds.; Pergamon: Oxford, 1991; Vol. 2, p 953.(b)Kleinman EF In Comprehensive Organic Synthesis; Trost BM, Fleming I, Eds.; Pergamon: Oxford, 1991; Vol. 2, p 893.(c)Overman LE; Ricca DJ In Comprehensive Organic Synthesis; Trost BM, Fleming I, Eds.; Pergamon: Oxford, 1991; Vol. 2, p 1007. 
<smiles>[R7]#CC=CC=Cc1cccnc1</smiles>

hydrogenation<smiles>[R7]c1ccc2c(c1)NCCC2</smiles><smiles>[R]C#CCC1=C(N)C=C[R7]C=C1</smiles><smiles>[R]C1CCc2cc[R17]([O-])cc2N1</smiles><smiles>[R3]C=CN=Cc1ccccc1</smiles><smiles>O=C(O)CCCC(=O)O[Na]</smiles><smiles>[R][R]1ccc2c(c1)C([R3])CC([R2])N2</smiles>

This work<smiles>[Y][X][N+](C)(C)c1c#[R]ccc1</smiles><smiles>O=C(O)COS(=O)(=O)OOOC(=O)C(=O)O</smiles><smiles></smiles>

Scheme 1.

Representative Synthetic Approaches to Tetrahydroquinolines 
a.

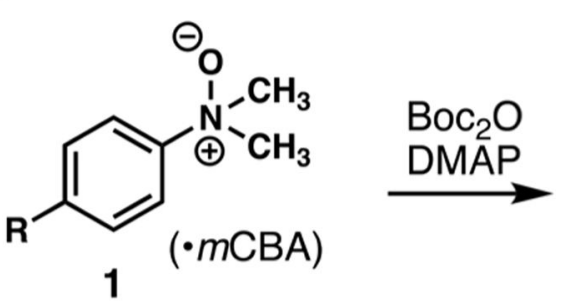<smiles>[R]c1ccc([N+](C)(C=C[CH]COC(C)(C)C)OC(=O)O[Al]CCCCC)cc1</smiles><smiles>[Y]CN(C)c1ccc([R])cc1</smiles><smiles>[Y]CC[N+](C)(C)c1ccc([R])cc1</smiles>

4

$3 a$<smiles>[Y]CN(C)c1ccc([R])cc1[Y]</smiles>

5<smiles>[Y]CN(C)c1ccc([R])cc1[X]</smiles>

b.

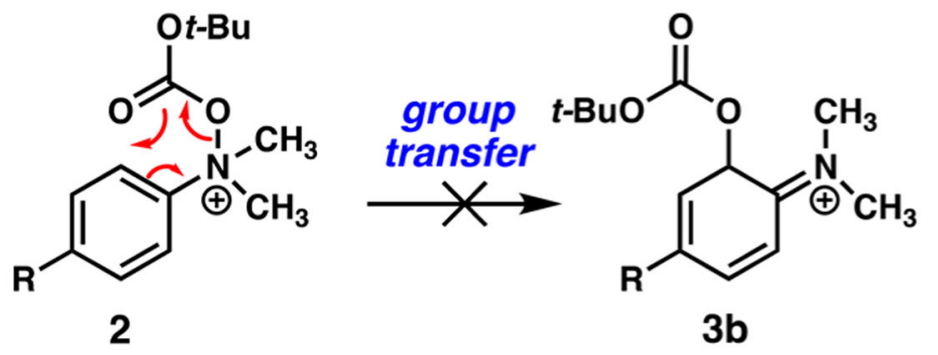

Scheme 2.

(a) Mechanism of the Tandem Polonovski-Povarov Reactions with Aniline $N$-Oxides. (b) Group-Transfer Reactions Avoided by Use of $\mathrm{Boc}_{2} \mathrm{O}$ 


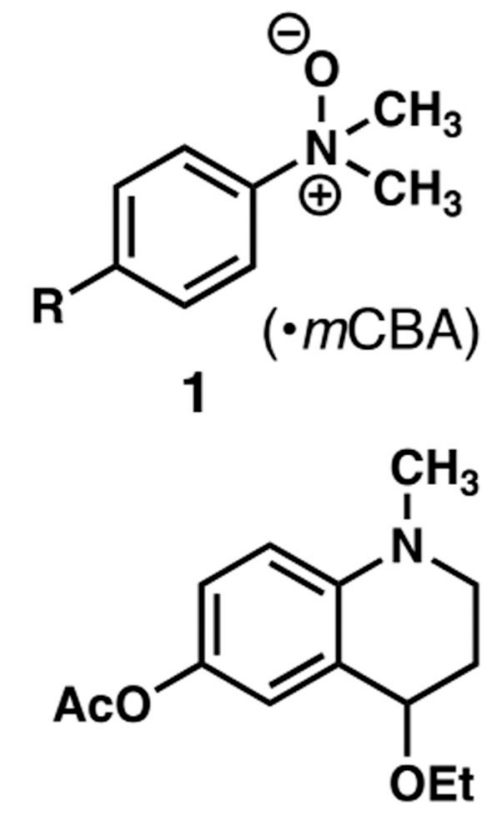

$7 a$

$78 \%$

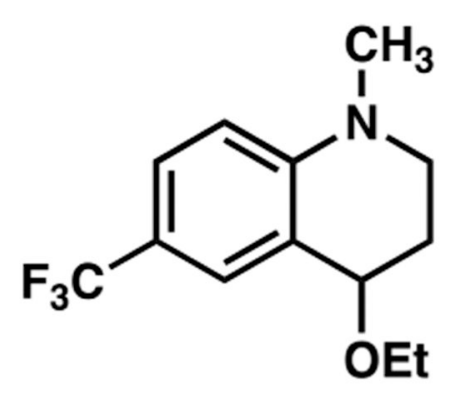

$7 d$ $56 \%$
1. $\mathrm{Boc}_{2} \mathrm{O}, \mathrm{DMAP}$, $\mathrm{CH}_{2} \mathrm{Cl}_{2}, 0^{\circ} \mathrm{C}$

2. ethyl vinyl ether, $\mathrm{SnCl}_{4}$, $-94 \rightarrow-78 \rightarrow 23^{\circ} \mathrm{C}$

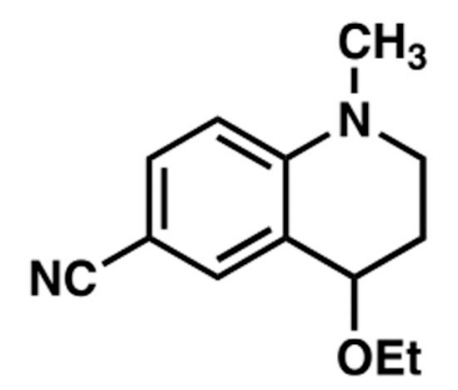

$7 b$

$42 \%$<smiles>[R]c1ccc2c(c1)C(OCC)CCN2C</smiles><smiles>CCOC1CCN(C)c2ccc(C(=O)OC)cc21</smiles>

7c $60 \%$<smiles>CCOC1CCN(C)c2ccc(Br)cc21</smiles>

$7 f$ $43 \%$

Scheme 3 .

Tandem Polonovski-Povarov Reactions Joining Aniline $N$-Oxides with Ethyl Vinyl Ether ${ }^{a}$ ${ }^{a}$ Yields of isolated products; reactions were performed on a $1 \mathrm{mmol}$ scale. 
<smiles>[R]c1ccc([N+](C)(C)[O-])cc1</smiles>

1. $\mathrm{Boc}_{2} \mathrm{O}$, DMAP

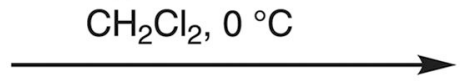

2. 2,3-dihydrofuran or

3,4-dihydro-2 $\mathrm{H}$-pyran,<smiles>CC(=O)Oc1ccc2c(c1)[C@H]1OCC[C@@H]1CN2C</smiles>

$\mathrm{SnCl}_{4},-94-7823^{\circ} \mathrm{C}$

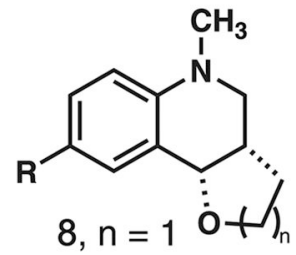<smiles>CN1C[C@@H]2CCO[C@H]2c2cc(N3C(=O)c4ccccc4C3=O)ccc21</smiles>

$8 a$

$74 \%$<smiles>CC=CCC=O</smiles><smiles>CC(=O)Oc1ccc2c(c1)[C@@H]1OCCC[C@H]1CN2C</smiles><smiles>CN1C[C@@H]2CCO[C@H]2c2cc([N+](=O)[O-])ccc21</smiles>

8 e

$9, n=2$<smiles>COC(=O)c1ccc2c(c1)[C@H]1OCC[C@@H]1CN2C</smiles>

$8 \mathrm{c}$<smiles>CN1C[C@H]2CCO[C@H]2c2cc(Br)ccc21</smiles>

$50 \%$<smiles>CN1C[C@H]2CCCO[C@H]2c2cc(C#N)ccc21</smiles>

$59 \%$

$62 \%$<smiles>CN1C[C@H]2CCCO[C@H]2c2cc(Br)ccc21</smiles>

9d

$9 \mathrm{e}$

$64 \%$

$72 \%$

Scheme 4.

Tandem Polonovski-Povarov Reactions Joining Aniline $N$-Oxides with Cyclic Vinyl Ethers ${ }^{a}$ ${ }^{a}$ Yields of isolated products; reactions were performed on a $1 \mathrm{mmol}$ scale. 
<smiles>[R]c1ccc([N+](C)(C)[O-])cc1</smiles>

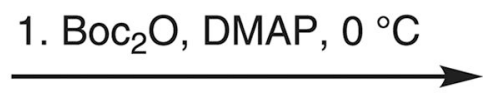

2. 2,3-benzofuran, $\mathrm{SnCl}_{4}$, $-7823^{\circ} \mathrm{C}$<smiles>[R]c1ccc2c(c1)[C@H]1c3ccccc3O[C@@H]1CN2C</smiles><smiles>CC(=O)Oc1ccc2c(c1)[C@H]1c3ccccc3O[C@H]1CN2C</smiles><smiles>CN1C[C@@H]2Oc3ccccc3[C@H]2c2cc(C#N)ccc21</smiles><smiles>COC(=O)c1ccc2c(c1)[C@H]1c3ccccc3O[C@H]1CN2C</smiles><smiles>CN1C[C@H]2Oc3ccccc3[C@H]2c2cc(C(F)(F)F)ccc21</smiles><smiles>CN1C[C@@H]2Oc3ccccc3[C@H]2c2cc(Br)ccc21</smiles><smiles>CN1C[C@H]2Oc3ccccc3[C@H]2c2cc(N3C(=O)c4ccccc4C3=O)ccc21</smiles><smiles>COC(=O)c1ccc2c(c1)[C@H]1c3cc(Br)ccc3O[C@H]1CN2C</smiles><smiles>CN1C[C@H]2Oc3ccc(Br)cc3[C@H]2c2cc(C(F)(F)F)ccc21</smiles>

Scheme 5.

Tandem Polonovski-Povarov Reactions Joining Aniline $N$-Oxides with Benzofuran. ${ }^{a}$ ${ }^{a}$ Yields of isolated products; reactions were performed on a $1 \mathrm{mmol}$ scale. 
<smiles>COC(=O)c1ccc([N+](C)(C)[O-])cc1</smiles><smiles>CCC1c2cc(C(=O)OC)ccc2N(C)CC1CCB1OC(C)(C)C(C)(C)O1</smiles><smiles>CCC1c2cc(C(=O)OC)ccc2N(C)CC1CCO</smiles><smiles>COC(=O)c1ccc2c(c1)C(c1ccc(OC)cc1)[C@@H](CC(C)(C)C)CN2C</smiles>

11c

$92 \%$<smiles>CC[C@H]1CN(C)c2ccc(C(=O)OC)cc2C1c1ccc2c(c1)OCO2</smiles>

11d $90 \%$

Scheme 6.

Reactions with Allylic Silanes as Nucleophiles ${ }^{a}$

${ }^{a}$ Yields of isolated products; reactions were performed on a $0.6 \mathrm{mmol}$ scale. 
a.<smiles>[R]c1ccc([N+](C)(C)[O-])cc1</smiles>

1a, $R=O A C$

1b, $\mathrm{R}=\mathrm{CH}_{3}$
1. $\mathrm{Boc}_{2} \mathrm{O}$, DMAP, $0^{\circ} \mathrm{C}$

2. $\mathrm{SnCl}_{4},-78^{\circ} \mathrm{C}$

3.<smiles>COC(OC)=C(C)C</smiles>

$-78 \rightarrow 23^{\circ} \mathrm{C}$<smiles>[R]OC(=O)C(C)(C)CN(C)c1ccc(P)cc1</smiles>

12a, $R=O A c, 96 \%$

12b, $\mathrm{R}=\mathrm{CH}_{3}, 64 \%$

b.

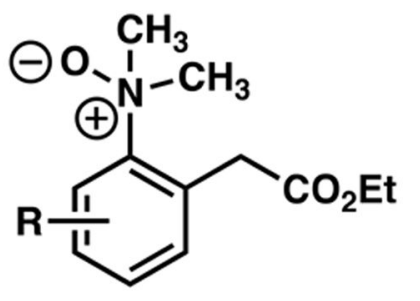

13

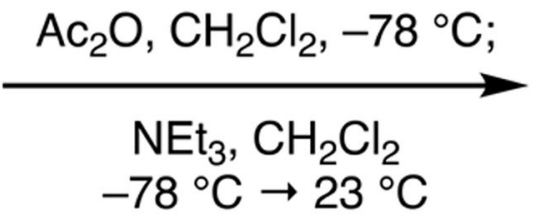

$-78^{\circ} \mathrm{C} \rightarrow 23^{\circ} \mathrm{C}$

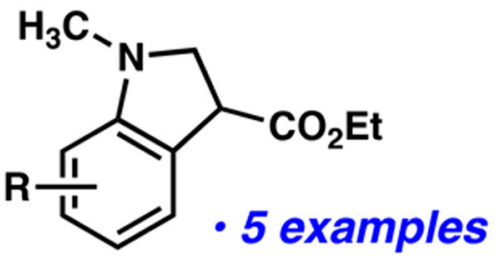

14

Scheme 7.

Mannich-Type Reactivity with Aniline $N$-Oxides 